\title{
STRATEGI PENGEMBANGAN KOMODITAS PINANG BERKELANJUTAN BERDASARKAN EVALUASI KESESUAIAN LAHAN DI KECAMATAN MOLLO UTARA, KABUPATEN TIMOR TENGAH SELATAN
}

\author{
Areca Nut Sustainable Development Strategy Based on Land Suitability Evaluation in \\ North Mollo Regency, South Central Timor Regency
}

\author{
Oskar K. Oematan', I.N. Prijo Soetedjo², \& Marthen R. Pellokila ${ }^{3}$
}

\begin{abstract}
North Mollo District is one of the areca nut-producing areas in the TTS Regency. Areca nut has high economic value and environmental services, but the communities has not cultivated this plant intensively. In order to maintain the availability of areca nut, community empowerment and land used planning according to biogeophysics, spatial, land availability, and socioeconomic aspects were needed. This study a imed to establish areca nut cultivation strategies based on land suitability evaluation. The methodology used in this study included biophysical variables with land suitability analysis based on FAO land evaluation procedures, vegetation variables using the Shannon diversity index formula, economic variables with the TEV (Total Economy Value) approach and areca nut sustainable cultivation strategies through SWOT analysis. The results showed that areca nut cultivation strategy based on the SWOT analysis was a strength opportunity (SO) strategy, in which this strategy utilizes the strengths and opportunities to develop areca nuts by developing existing areca nut, and increasing the government's role in areca nut to promote the sustainable of areca nut management.
\end{abstract}

Keywords : Areca nut, cultivation, strategy, sustainability, North Mollo

\begin{abstract}
ABSTRAK
Kecamatan Mollo Utara merupakan salah satu daerah penghasil pinang di Kabupaten TTS. Pinang memiliki nilai ekonomi dan jasa lingkungan yang tinggi, namun masyarakat belum membudidayakan tanaman pinang secara intensif. Agar ketersediaan tanaman pinang ini selalu terjaga, maka diperlukan upaya pemberdayaan masyarakat serta perencanaan tataguna lahan sesuai kriteria tumbuh tanaman (biogeofisik), aspek spasial (tata ruang), ketersediaan lahan dan aspek sosial ekonomi. Penelitian ini bertujuan untukuntuk menyusun strategi pengembangan tanaman pinang berdasarkan evaluasi kesesuaian lahan. Metodologi yang digunakan dalam penelitian ini meliputi variabel biogeofisik dengan analisis kesesuaian lahan berdasarkan prosedur evaluasi lahan Food and Agriculture Organization (FAO), variabel vegetasi menggunakan rumus indeks keanekaragaman Shannon, variabel ekonomi dengan pendekatan TEV (Total Economy Value) dan strategi pengembangan tanaman pinang secara berkelanjutan melalui analisis SWOT. Hasil penelitian menunjukan Strategi pengembangan pinang berdasarkan analisis SWOT adalah strategi strength opportunity (SO), dimana strategi ini memanfaatkan kekuatan dan peluang untuk mengembangkan pinang dengan mengembangkan vegetasi yang ada melalui penanaman pinang, dan meningkatkan peran pemerintah dalam pengembangan pinang sehingga tercapai pengelolaan pinang yang berkelanjutan.
\end{abstract}

Kata Kunci : Pinang, pengembangan, strategi, keberlanjutan, Mollo Utara

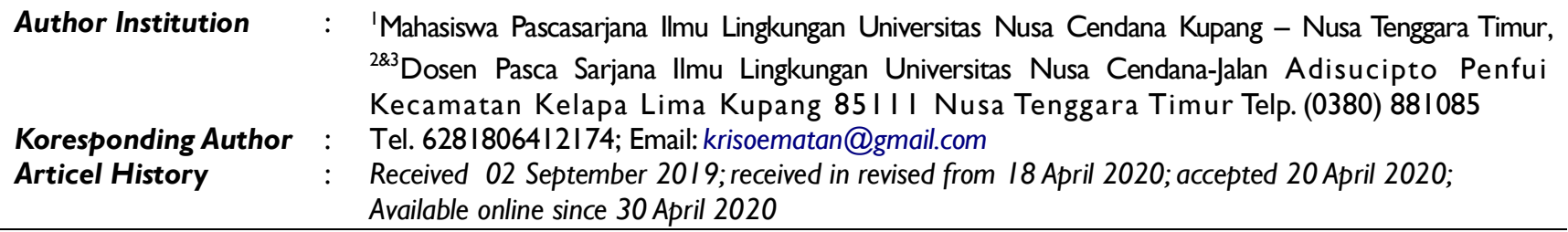




\section{PENDAHULUAN}

Pinang merupakan tumbuhan yang banyak dijumpai di Nusa Tenggara Timur dan banyak dimanfaatkan oleh masyarakat terutama berkaitan dengan budaya lokal nginang dan upacara adat. Kecamatan Mollo Utara merupakan salah satu daerah penghasil pinang di Kabupaten Timor Tengah Selatan. Daya tumbuh dan produksi tanaman pinang sangat tergantung pada kondisi lingkungan atau karakteristik lahan (iklim, biofisik, sosial ekonomi dan sosial budaya). Berdasarkan data jenis penggunaan lahan Balai Pemantapan Kawasan Hutan wilahan XIV Kupang (BPKH, 20I8) Kecamatan Mollo Utara didominasi oleh kawasan pertanian dan perkebunan dengan persentase mencapai 36,19\%. Sedangkan tataguna lainnya seperti hutan primer dan hutan sekunder mencapai $34,05 \%$, savana padang rumput 23, $14 \%$, semak dan tanah kosong 6, I5\%, dan pemukiman 0,47\%. Menurut Basuki dan Nulik (2007) kondisi tanah di Kecamatan Mollo Utara didominasi oleh Kambisol ustik dengan luasan $13.973,96$ ha $(82,7 \%)$, tanah Renzina dengan luasan $1.423,1$ I\% ha $(8,44 \%)$, Kambisol Distrik dengan luasan 784,03 ha (4,65\%), tanah Alluvial dengan luasan 636.24 ha $(3,77 \%)$ dan sisanya adalah jenis Mediteran haplik 72,88 ha $(0,43 \%)$.

Topografi di wilayah Kabupaten TTS didominasi wilayah dengan kemiringan lereng $15-25 \%$ (agak curam) yang mencakup luasan $1.897 \mathrm{~km}^{2}$ atau 48,36\% dari total wilayah. Wilayah Kecamatan Mollo Utara terletak pada ketinggian 1007 meter dari permukaan laut, dengan topografi yang didominasi oleh kemiringan lereng 15-25\% (agak curam) (BPDAS, 20I2). Secara umum kondisi iklim di Kecamatan Mollo Utara, menurut sistem klasifikasi iklim Koppen termasuk tipe iklim Aw (iklim basah tropik/tropical wet and dry climate). Daerah ini merupakan daerah terbasah di daratan Timor dengan lima bulan kering dan tujuh bulan basah. Curah hujan berkisar antara 1500- $2000 \mathrm{~mm}$ per tahun dengan jumlah hari hujan 100-150 hari per tahun (BMKG, 2019). Karakteristik lahan tersebut nampaknya berhubungan dengan kondisi iklim yang ada, di wilayah Kecamatan Mollo Utara tergolong sesuai untuk pertumbuhan dan perkembangan tanaman pinang. Menurut Staples \& Bevacqua (2006) tanaman pinang dapat tumbuh pada ketinggian mulai dari I meter sampai dengan I.400 meter di atas permukaan laut, dapat tumbuh dengan subur pada iklim tropis dengan pengaruh kondisi laut dan tumbuh optimal pada ketinggian 900 meter di atas permukaan laut.

Kesesuaian lahan dan iklim pada lingkungan tersebut didukung oleh kondisi sosial budaya masyarakat di Kecamatan Mollo Utara. Tradisi masyarakat Mollo yang menjadikan pinang sebagai bagian yang harus ada dalam setiap aktivitas masyarakat (Salukh, 2017). Namun fakta dilangan menujukan bahwa masyarakat di Kecamatan Mollo Utara belum menjadikan pinang sebagai komoditas prioritas untuk dibudidayakan. Padahal pinang memiliki nilai ekonomi dan jasa lingkungan yang tinggi serta bisa dikatakan sebagai salah satu kebutuhan pokok. Masyarakat belum membudidayakan tanaman pinang secara intensif dan masih mengandalkan tanaman pinang yang tumbuh secara alami. Oleh karena itu untuk memenuhi kebutuhan pinang harus didatangkan dari daerah lain. Penelitian ini bertujuan untuk menyusun strategi pengembangan tanaman pinang berdasarkan evaluasi kesesuaian lahan. 
II. METODE PENELITIAN

\section{A. Lokasi dan Waktu Penelitian}

Penelitian ini dilakukan di Kecamatan
Mollo Utara, Kabupaten Timor Tengah Selatan pada tahun 2019. Peta lokasi penelitian seperti pada Gambar I.

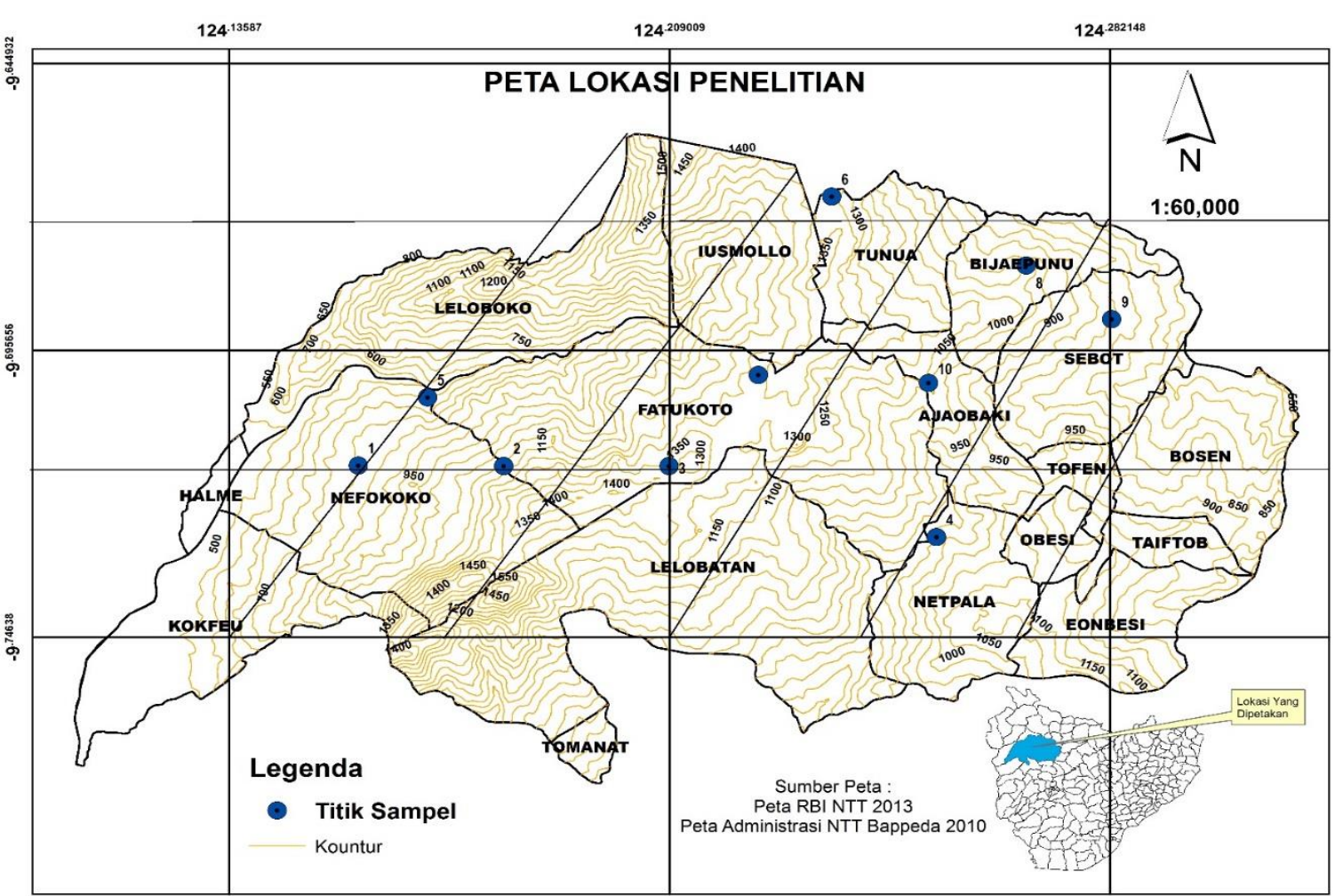

Gambar I.Peta lokasi penelitian (Sumber:Peta administrasi Bappeda NTT 20 I0, data diolah 2019 Figure I. Map of research location (Source: Map of Bappeda NTT 2010 administration, data processed, 2019)

\section{B. Alat dan Bahan}

Evaluasi kesesuaian lahan dengan tujuan untuk memperoleh kebutuhan sumber daya biofisik lahan (iklim dan tanah) tanaman pinang dengan penentuan kelas kesesuaian dilakukandengan metode pencocokan karakteristik lahan dan persyaratan tumbuh komoditas perkebunan (Djaenudin et al., 20I I). Bahan yang digunakan dalam penelitian ini adalah lahan budidaya dan pengembangan tanaman pinang (Areca catechu LINN), sedangkan alat yang digunakan adalah sekop, cangkul, parang, ring sampel, besi gali, isolasi bening, alat tulis, Global Positioning System (GPS), data peta jenis tanah, kelerengan, tutupan dan penggunaan lahan, dan data curah hujan lima tahun terakhir.

\section{Metodologi}

\section{Sumber data}

Penelitian ini menggunakan data primer yang diperoleh melalui pengamatan langsung di lapangan berupa kuisioner, wawancara dan survei. Sedangkan data sekunder berasal dari berbagai instansi yang berkaitan dengan pengembangan tanaman pinang. Penentuan lokasi lahan yang ada (existing), yang 
berpotensi untuk pengembangan tanaman pinang dilakukan dengan survei lapangan, berdasarkan pada aspek biofisik, ekonomi, sosial dan ketersediaan lahan menggunakan peta penggunaan lahan yang ada (existing), satuan peta lahan (land unit), peta penunjukan kawasan hutan, peta administrasi, dan kriteria kesesuaian lahan tanaman pinang.

\section{Pengambilan sampel}

Metode pengambilan sampel yang digunakan adalah stratified random sampling sebanyak 10 titik sampel dalam 3 strata. Strata ketinggian yang dipilih yaitu: $\mathrm{TI}=750$ 1000 mdpl (Desa Nefokoko, Desa Bijaepunu dan Desa Sebot), T2 = I000-1250 mdpl (Desa Fatukoto, Desa Netpala dan Desa Aajobaki) dan T3 = I250-I500 mdpl (Desa Tunua). Pengukuran vegetasi menggunakan nilai indeks keanekaragaman ShannonWiener $\left(\mathrm{H}^{\prime}\right)$. Data sosial ekonomi dikumpulkan melalui wawancara untuk menentukan total nilai ekonomi pinang dengan menggunakan teknik purposive sampling. Dalam penelitian ini dilakukan wawancara terhadap 70 orang responden, yang termasuk 7 informan (tokoh masyarakat).

\section{Analisa data}

Metodologi yang digunakan dalam penelitian ini meliputi variabel biogeofisik dengan menggunakan analisis kesesuaian lahan berdasarkan prosedur evaluasi lahan Food and Agriculture Organization (FAO, 1976), variabel vegetasi menggunakan rumus indeks keanekaragaman Shannon, variabel ekonomi dengan pendekatan TEV (Total Economy Value) dan strategi pengembangan tanaman pinang secara berkelanjutan melalui analisis SWOT.

\section{HASIL DAN PEMBAHASAN}

\section{A. Karakteristik Lahan}

Secara geografis letak Kecamatan Mollo Utara berada di bagian utara wilayah administrasi Kabupaten Timor Tengah Selatan. Karakteristik lahan pada lokasi penelitian terdiri dari karakteristik fisik dan kimia tanah yang meliputi tekstur tanah, porositas tanah, kemantapan agregat tanah, reaksi tanah $(\mathrm{pH})$, nitrogen, fosfor, dan kalium dapat dilihat pada Tabel I.

Berdasarkan hasil uji laboratorium tanah fakultas Pertanian Undana pada Tabel I di bawah tekstur tanah didominasi oleh tekstur halus berupa lempung, dan lempung berpasir. Porositas tanah di lokasi penelitian mulai dari kurang baik terdapat di Desa Nefokoko, Sebot dan Netpala, porositas baik terdapat di Desa Fatukoto, Ajaobaki, Tunua dan yang poros di Desa Nefokoko. Kemantapan agregat tanah menunjukkan cukup beragam yaitu pada masing-masing unit lahan berkisar antara 1749,90 terendah terdapat di Desa Nefokoko dan tertinggi 2693,59 di Desa Nefokoko. Rekasi Tanah (pH tanah). menunjukkan bahwa $\mathrm{pH}$ tanah di wilayah penelitian sangat beragam mulai dari masam $(5,02)$ di Desa Ajaobaki sampai agak alkalis $(8,18)$ di Desa Sebot. Kandungan Nitrogen di lokasi peneltian cukup beragam, masing-masing unit lahan berkisar antara 0,18\% terendah terdapat di Desa Fatukoto dan tertinggi 0,31\% di Desa Nefokoko atau rendah sampai sedang. Ketersedian Fosfor (P) kadar $\mathrm{P}_{2} \mathrm{O}_{5}$ seluruhnya termasuk kategori rendah 20,78 terdapat di Desa Fatukoto sampai sangat tinggi 53,57 di Desa Nefokoko, namun berbeda untuk setiap unit lahan. Perbedaan ini disebabkan oleh karena kadar Fosfor di dalam tanah umumnya rendah dan berbeda-beda menurut tipe tanah. 
Tabel I. Karakteristik fisik dan kimia tanah pada lokasi penelitian

Table I. Physical and chemical characteristics of the soil at the study site

\begin{tabular}{|c|c|c|c|c|c|c|c|c|}
\hline No & $\begin{array}{c}\text { Kode } \\
\text { sampel } \\
\text { (Desa) }\end{array}$ & $\begin{array}{r}\begin{array}{r}\text { Bahan organik } \\
\text { (Organic matter) }\end{array} \\
\ldots . . \% \ldots . . .\end{array}$ & $\mathbf{N}$ total & $\begin{array}{c}P \text { - } \\
\text { tersedia } \\
(\mathbf{p p m})\end{array}$ & $\begin{array}{l}\text { K - dd } \\
(\mathrm{cmol} \\
(+) / \mathrm{kg}\end{array}$ & PH & $\begin{array}{c}\text { Porositas } \\
\text { (\%) }\end{array}$ & $\begin{array}{c}\text { Kemantapan } \\
\text { Agregat } \\
\text { (EK=mgh) } \\
\text { (Vilensky }\end{array}$ \\
\hline & Strata I & & & & & & & \\
\hline I & Nefokoko & 4,28 & $0,31 \mathrm{~S}$ & $53,57 \mathrm{ST}$ & $\mathrm{I}, 12 \mathrm{R}$ & $7,4 \mid \mathrm{N}$ & $46,08 \mathrm{~KB}$ & 2432,55 \\
\hline 2 & Nefokoko & 3,70 & $0,27 \mathrm{~S}$ & $43,45 \mathrm{ST}$ & $0,95 \mathrm{SR}$ & $7,43 \mathrm{~N}$ & $60,59 P$ & 1749,90 \\
\hline 5 & Nefokoko & 2,88 & $0,22 \mathrm{~S}$ & $31,74 \mathrm{~T}$ & $0,77 \mathrm{SR}$ & $7,83 \mathrm{AA}$ & $42,15 \mathrm{~KB}$ & 2693,59 \\
\hline 9 & Sebot & 1,16 & $0,24 \mathrm{~S}$ & $20,93 \mathrm{~T}$ & 0,47 SR & $8,18 \mathrm{AA}$ & $45,35 \mathrm{~KB}$ & 2621,12 \\
\hline \multirow[t]{2}{*}{8} & Bijaepunu & 0,09 & $0,28 \mathrm{~S}$ & $26,05 \mathrm{~T}$ & $0,25 \mathrm{SR}$ & $8, I \mid A A$ & $51,75 \mathrm{~B}$ & 2360,04 \\
\hline & Strata II & & & & & & & \\
\hline 3 & Fatukoto & $|, 9|$ & $0,18 \mathrm{R}$ & $20,78 \mathrm{~S}$ & 0,62 SR & $7,19 \mathrm{~N}$ & $5 I, 04$ B & 2305,33 \\
\hline 7 & Fatukoto & 2,58 & $0,21 \mathrm{~S}$ & $28,85 \mathrm{~T}$ & 0,73 SR & $5, I I M$ & $51,54 \mathrm{~B}$ & 2247,96 \\
\hline 10 & Ajaobaki & 2,47 & $0,20 \mathrm{R}$ & $26,21 \mathrm{~T}$ & $0,68 \mathrm{SR}$ & $5,02 M$ & $53,54 \mathrm{~B}$ & 2155,40 \\
\hline \multirow[t]{2}{*}{4} & Netpala & 2,36 & $0,21 \mathrm{~S}$ & $27,58 \mathrm{~T}$ & $0,73 \mathrm{SR}$ & $6,95 \mathrm{~N}$ & $43,94 \mathrm{~KB}$ & 2631,73 \\
\hline & Strata III & & & & & & & \\
\hline 6 & Tunua & 4,36 & $0,30 \mathrm{~S}$ & $5 \mathrm{I}, \mathrm{II} \mathrm{ST}$ & $\mathrm{I}, 07 \mathrm{R}$ & $6,74 \mathrm{~N}$ & $54,30 \mathrm{~B}$ & 2025,65 \\
\hline
\end{tabular}

Sumber/Source : olahan data primer, 2019 (Primary data processed, 2019)

Keterangan (Remarks): SR (Sangat rendah), R (Rendah), S (Sedang ),T (Tinggi), ST (Sangat tinggi), SM (Sangat masam) M (Masam), AM (Agak masam), N (Netral), AA (Agak alkalis), A (Alkalis), SP (Sangat poros), P (Poros), B (Baik), KB (Kurang baik), J (Jelek), SJ (Sangat jelek)

Tanah-tanah muda biasanya lebih tinggi daripada tanah-tanah yang tua. Kalium (K) kadar $\mathrm{K}_{2} \mathrm{O}$ yang sangat rendah sebesar 0,25 terdapat di Desa Bijaepunu dan rendah sebesar I, 12 terdapat di Desa Nefokoko atau pada umumnya untuk semua unit lahan pada lokasi penelitian. Perkebunan pinang memiliki kemampuan untuk memulihkan tanah ke kondisi aslinya baik sifat fisik maupun kimia tanah sehingga dapat memperbaiki produksi pinang secara berkelanjutan (Mawii et al., 2017).

\section{B. Indeks Keanekaragaman Vegetasi}

Sesuai dengan kondisi lingkungannya, flora di suatu tempat dapat terdiri dari beragam jenis yang masing-masing dapat terdiri dari beragam variasi gen yang hidup di beberapa tipe habitat. Kriteria yang digunakan untuk menginterpretasikan keanekaragaman Shannon-Wiener yaitu: $H^{\prime}<$ I menunjukkan tingkat keanekaragaman yang rendah, $\mathrm{H}^{\prime}=\mathrm{I}-3$ menunjukkan tingkat keanekaragaman tergolong sedang dan $\mathrm{H}^{\prime}>3$ menunjukkan tingkat keanekaragamannya tergolong tinggi (Odum, 1996). Dari kriteria di atas terlihat bahwa tingkat keanekaragaman jenis vegetasi di wilayah Kecamatan Mollo Utara secara keseluruhan untuk tingkatan pertumbuhan pohon memiliki tingkat keanekaragaman jenis yang tinggi $(3,35)$, sedangkan untuk tingkat pertumbuhan semai $(2,24)$, pancang $(2,54)$ dan tiang $(1,73)$ termasuk dalam golongan sedang. Dengan demikian semakin beragam vegetasi dan semakin rapat atau padatnya tutupan vegetasi suatu lahan memberikan distribusi bahan organik yang melimpah. Di samping itu banyaknya vegetasi akan 
memberikan pengaruh positif terhadap banyaknya ruang pori dalam tanah sehingga laju infiltrasi tanah semakin besar. Hal tersebut berfungsi mengurangi laju aliran permukaan (run off) karena air hujan tidak akan langsung jatuh mengenai permukaan tanah. Hal itu sejalan dengan pernyataan (Asdak, 20l4) bahwa bagian air hujan yang diintersepsi vegetasi akan menguap ke udara, yang berarti mengurangi banyaknya air hujan yang jatuh ke permukaan tanah sehingga mengurangi aliran permukaan dan mengurangi butir air hujan terhadap tanah. Oleh karena itu semakin banyak kerapatan, keanekaragaman, kekayaan, dan keseragaman jenis suatu vegetasi dapat meningkatkan laju infiltasi dengan baik.

\section{Total Ekonomi Valuasi Pinang}

Keberadaan tanaman pinang secara umum di Kecamatan Mollo Utara memberikan manfaat yang besar bagi masyarakat. Menurut Sihombing (2000) secara keseluruhan pinang dapat dimanfaatkan untuk berbagai kebutuhan. Daunnya mengandung minyak atsiri yang dapat digunakan untuk mengobati gangguan tenggorokan, pelepahnya sebagai bahan baku pembungkus makanan, batangnya sebagai bahan bangunan. Sementara itu serabut buahnya dapat digunakan untuk kuas, dan bijinya untuk bahan makanan, obat, pewarna kain dan untuk kebutuhan nginang. Bentuk pendekatan dalam melihat nilai ekonomi pinang pada pembahasan ini yaitu dengan melakukan valuasi ekonomi untuk mendapatkan nilai ekonomi total (TEV). Nilai ekonomi total pohon pinang meliputi lima kategori yaitu: (I) nilai manfaat langsung atau direct use value (DUV), (2) nilai manfaat tidak langsung atau indirect use value (IUV), (3) nilai manfaat pilihan atau option value (OV), (4) nilai manfaat keberadaan atau existence value (EV) dan (5) nilai warisan atau bequest value (BV)(Pearce, 1992) dikutip dari Nurfatriani, (2006) :

I. Manfaat langsung. Buah pinang dapat dimakan langsung dalam hal ini untuk kebutuhan nginang. Dalam satu pohon pinang terdapat empat tandan dengan masing-masing tandan memiliki buah mencapai 50 buah, sehingga dihitung satu pohon pinang memiliki 200 buah dengan harga Rp5.000,00/5- 6 buah sehingga per buahnya RpI.000,00, jadi dalam satu pohon pinang dapat menghasilkan $200 \times 1000=$ Rp200.000,00, hal ini dilakukan selama 2 kali panen dalam setahun, sehingga dapat menghasilkan sebesar Rp400.000,00, Batang pinang yang sudah tua dan tidak berproduksi lagi biasanya dijual dengan harga per pohon sebesar Rp50.000,00. sehingga total manfaat langsung Rp450.000,00/pohon (Tabel 2)

2. Manfaat tidak langsung, diperoleh dari unsur-unsur sebagai berikut : untuk pohon peneduh Rp4.630.000,00, konservasi tanah dan air Rp3.535.000,00 dan penyerapan karbon Rp3.535.000,00 maka nilai tersebut kemudian dijumlahkan sehingga diperoleh hasil sebesar Rp. I I.680.000 per tahun.

3. Manfaat warisan, dari hasil wawancara responden memberikan nilai warisan untuk pohon pinang adalah Rp500.000,00/pohon dengan alasan anak cucu dapat melestarikan dan meneruskan nilai budaya orang Timor.

4. Manfaat pilihan dan keberadaan, berdasarkan wawancara dengan responden mereka menganggap bahwa kedua manfaat tersebut sudah terwakilkan dalam manfaat warisan.

Berdasarkan hasil kuantifikasi nilai ekonomi sumberdaya pinang di Kecamatan 
Mollo Utara, maka nilai ekonomi total sumberdaya pinang tersebut diperoleh sebesar Rpl2.630.000,00 per pohon/tahun.
Nilai ekonomi total sumberdaya pinang Kecamatan Mollo Utara dapat dilihat pada Tabel 2 di bawah ini.

Tabel 2. Nilai ekonomi total sumberdaya pinang di Kecamatan Mollo Utara Table 2. The total economic value of areca nut resources in North Mollo District

\begin{tabular}{|c|c|c|c|}
\hline No & $\begin{array}{l}\text { Jenis manfaat } \\
\text { (Types of benefits) }\end{array}$ & $\begin{array}{c}\text { Nilai Ekonomi } \\
\text { (Economic Value) } \\
(R p)\end{array}$ & $\begin{array}{c}\text { Persentase } \\
\text { (Percentage) } \\
\text { (\%) }\end{array}$ \\
\hline $\mathrm{I}$ & Manfaat langsung & $450.000,00$ & 3,56 \\
\hline 2 & Manfaat tidak langsung (non market) & $11.680 .000,00$ & 92,48 \\
\hline 3 & Manfaat pilihan & - & \\
\hline 4 & Manfaat keberadaan & - & \\
\hline \multirow[t]{2}{*}{5} & Manfaat warisan & $500.000,00$ & 3,96 \\
\hline & Nilai Total (Total Value) & $12.630 .000,00$ & 100 \\
\hline
\end{tabular}

Sumber/Source : olahan data primer, 2019 (Primary data processed, 2019)

Berdasarkan data di atas terdapat perbedaan yang cukup besar antara nilai ekonomi pinang yang dimanfaatkan secara langsung dengan manfaat pinang secara tidak langsung maupun nilai warisannya. Hal ini menunjukkan bahwa sumberdaya pinang memiliki peranan penting dalam memberikan kontribusi ekonomi secara langsung dalam menopang terpenuhinya kebutuhan konsumsi pinang masyarakat di Kecamatan Mollo Utara, nilai manfaat langsung masih terlihat kecil sehingga perlu dilakukan pelestarian dan pengembangan pinang karena berdasarkan hasil wawancara kebutuhan makan pinang masyarakat Mollo Utara pada umumnya berkisar atara Rp5.000,00-10.000,00/ orang/hari. Sedangkan manfaat tidak langsung pinang nilainya relatif lebih tinggi menunjukkan bahwa pinang memiliki nilai dari jasa lingkungannya yang cukup tinggi. Menurut (Yuliantoro et al., 2016) pohon yang ditanam di sekitar mata air berfungsi menjaga kelestarian mata air dan tersedianya air di daerah tersebut. Kondisi tersebut mendorong masyarakat memiliki keinginan untuk melakukan pelestarian dan pengembangan tanaman pinang dimasa mendatang.

\section{Kesesuaian Lahan Pinang}

Klasifikasi kesesuaian lahan aktual adalah sistem klasifikasi kesesuaian lahan yang pengelompokannya didasarkan pada karakteristik lahan yang ada pada saat itu, tanpa mempertimbangkan input yang dibutuhkan. Parameter penentuan kelas kesesuaian lahan di Kecamatan Mollo Utara tertera di Tabel 3 di bawah ini.

Berdasarkan panduan (Djaenudin et al., 20II) komoditas yang dipilih harus sesuai dengan kondisi biofisik, dan menguntungkan secara ekonomi untuk dibudidayakan, serta penerapan teknologi pengelolaan lahan untuk tiap wilayah berdasarkan karakteristik lahan dan lingkungannya. Pemilihan wilayah berdasarkan sifat-sifat tanah dan lingkungan (zona-zona satuan lahan) akan banyak membantu ke daerah mana suatu paket teknologi yang telah dirakit untuk kondisi fisik lingkungan tertentu dapat diaplikasikan. Satu komoditas yang dikembangkan dikatakan 
Tabel 3. Parameter penentuan kelas kesesuaian lahan di Kecamatan Mollo Utara Table 3. Parameters for determining land suitability classes in North Mollo District

\begin{tabular}{|c|c|c|c|c|c|c|c|c|c|c|}
\hline \multirow[b]{2}{*}{$\begin{array}{l}\text { Karakteristik } \\
\text { Lahan }\end{array}$} & \multicolumn{10}{|c|}{$\begin{array}{l}\text { Nilai data setiap satuan lahan } \\
\text { (Data value for each unit of land) }\end{array}$} \\
\hline & I & 2 & 3 & 4 & 5 & 6 & 7 & 8 & 9 & 10 \\
\hline \multicolumn{11}{|l|}{ Temperatur (tc) } \\
\hline \multicolumn{11}{|l|}{ Temperatur } \\
\hline Rerata $\left({ }^{\circ} \mathrm{C}\right)$ & $20-27$ & $20-27$ & $20-25$ & $20-28$ & $23-28$ & $18-24$ & $20-27$ & $20-26$ & $20-27$ & $20-28$ \\
\hline Ketinggian(mdpl) & 764 & 950 & 1150 & 1050 & 754 & 1300 & 1010 & 938 & 871 & 1070 \\
\hline Kelerengan (\%) & $8-15$ & $15-25$ & $15-25$ & $8-15$ & $8-15$ & $>40$ & $8-15$ & $15-25$ & $15-25$ & $15-25$ \\
\hline \multicolumn{11}{|l|}{$\begin{array}{l}\text { Ketersediaan } \\
\text { air (wa) }\end{array}$} \\
\hline $\begin{array}{l}\text { Curah hujan (mm) } \\
\text { Keterdiaan } \\
\text { oksigen (oa) }\end{array}$ & \multicolumn{10}{|c|}{$1590-2308$} \\
\hline Porositas (\%) & 46,08 & 60,59 & 51,04 & 43,94 & 42,15 & 54,30 & 51,54 & - 51,75 & 45,35 & 53,54 \\
\hline \multicolumn{11}{|l|}{ Media } \\
\hline \multicolumn{11}{|l|}{ Perakaraan (rc) } \\
\hline Tekstur & \multicolumn{10}{|c|}{ Lempung berpasir } \\
\hline \multicolumn{11}{|l|}{ Retensi hara (na) } \\
\hline $\mathrm{pH} \mathrm{H} 2 \mathrm{O}$ & 7,41 & 7,43 & 7,19 & 6,95 & 7,83 & 6,74 & $5, I I$ & 8,11 & 8,18 & 5,02 \\
\hline C-organik (\%) & 4,28 & 3,70 & 1,91 & 2,36 & 2,88 & 4,36 & 2,58 & 1,09 & 1,16 & 2,47 \\
\hline \multicolumn{11}{|l|}{$\begin{array}{l}\text { Ketersediaan } \\
\text { hara (na) }\end{array}$} \\
\hline N-Total(\%) & 0,31 & 0,27 & 0,18 & 0,21 & 0,22 & 0,30 & 0,21 & 0,28 & 0,24 & 0,20 \\
\hline P2O5 (ppm) & 53,57 & 43,45 & 20,78 & 27,58 & 31,74 & $5 I, I I$ & 28,85 & 26,05 & 20,93 & 26,21 \\
\hline $\mathrm{K}(\mathrm{cmol} / \mathrm{kg})$ & 1,12 & 0,95 & 0,62 & 0,73 & 0,77 & 1,07 & 0,73 & 0,25 & 0,47 & 0,68 \\
\hline Kelas kesesuaian & SI & SI & S3 & S2 & S3 & $\mathrm{N}$ & $\mathrm{SI}$ & SI & SI & S2 \\
\hline
\end{tabular}

Sumber/Source : olahan data primer (Primary data processed), (2019)

berkelanjutan apabila lahan yang dipergunakan untuk pengembangannya digunakan dengan tepat dan cara pengelolaannya yang sesuai. Penentuan lokasi yang berpotensi dalam pengembangan tanaman pinang di Kecamatan Mollo Utara (Tabel 4) berdasarkan aspek biofisik dan ketersediaan lahan yaitu dengan memadukan berbagai peta tematik dan menggunakan Sistem Informasi Geografis. Analisis kesesuaian lahan aktual tanaman pinang secara spasial dapat dilihat pada Gambar 2.
Hasil pencocokan digambarkan dalam bentuk pemetaan sehingga diperoleh luas masing-masing kelas kesesuaian, kelas SI dengan luas 4079.12 ha atau $43,15 \%$, S2 dengan luas 3017.98 ha atau $31,93 \%$, S3 dengan luas 1594.94 ha atau $16,87 \%$ dan $\mathrm{N}$ dengan luas 760,52 ha atau $8.05 \%$ dari total luas wilayah Kecamatan Mollo Utara. Distribusi luas menurut desa pada setiap kelas kesesuaian lahan untuk pengembangan tanaman pinang di Kecamatan Mollo Utara dapat dilihat pada Tabel 4. 


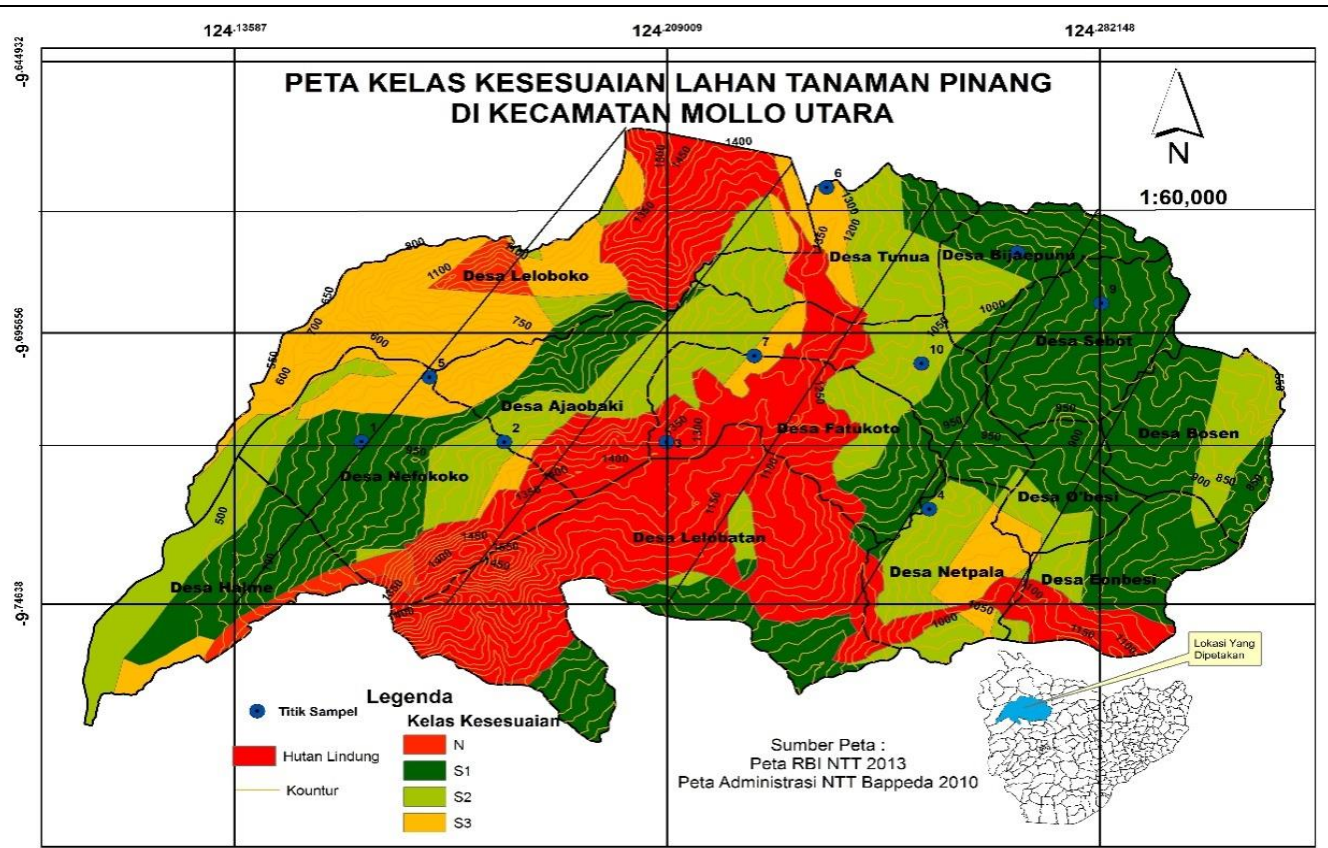

Gambar 2. Peta kesesuaian lahan aktual tanaman pinang di Kecamatan Mollo Utara (Sumber : Olahan data primer 2019

Figure 2. Map of actual land suitability of areca nut plants in North Mollo District (Source : Primary data processed 2019 )

Tabel 4. Luasan lahan berdasarkan kelas kesesuaian lahan pada tingkat desa Table 4. Land size based on land suitability class at village level

\begin{tabular}{|c|c|c|c|c|c|c|}
\hline \multirow{2}{*}{ No } & \multirow{2}{*}{ Desa (Villages) } & \multicolumn{4}{|c|}{ Kelas Kesesuaian (Class Suitability) (ha) } & \multirow{2}{*}{$\begin{array}{l}\text { Luas total (Total } \\
\text { area)(ha) }\end{array}$} \\
\hline & & $\mathbf{S I}$ & S2 & S3 & $\mathbf{N}$ & \\
\hline $\mathrm{I}$ & Ajaobaki & 341.04 & 18.26 & 29.09 & 0.00 & 388.39 \\
\hline 2 & Bijaepunu & 454.40 & 182.87 & 0.00 & 0.00 & 637.27 \\
\hline 3 & Bosen & 592.50 & 311.30 & 0.00 & 0.00 & 903.80 \\
\hline 4 & Eonbesi & 54.17 & 179.22 & 3.65 & 0.00 & 237.04 \\
\hline 5 & Fatukoto & 34.90 & 363.51 & 549.15 & 0.00 & 947.56 \\
\hline 6 & lusmollo & 6.88 & 177.24 & 322.84 & 0.91 & 507.87 \\
\hline 7 & Kokfeu & 507.82 & 367.36 & 0.08 & 41.67 & 916.92 \\
\hline 8 & Lelobatan & 433.7I & 888.95 & $256.4 I$ & 508.62 & 2087.70 \\
\hline 9 & Leloboko & 21.21 & 127.30 & 117.91 & 128.38 & 394.81 \\
\hline 10 & Nefokoko & 2.85 & 38.07 & 193.46 & 80.94 & 315.32 \\
\hline II & Sebot & 960.29 & 0.01 & 0.00 & 0.00 & 960.31 \\
\hline 12 & Netpala & 7.95 & 117.70 & 25.93 & 0.00 & 151.58 \\
\hline 13 & Obesi & 62.71 & $|07.3|$ & 38.75 & 0.00 & 208.78 \\
\hline 14 & Taiftob & 190.70 & 45.53 & 0.00 & 0.00 & 236.22 \\
\hline 15 & Tomanat & 101.53 & 0.00 & 0.00 & 0.00 & 101.53 \\
\hline 16 & Tunua & 129.02 & 0.36 & 38.85 & 0.00 & 168.24 \\
\hline 17 & Tofen & 177.45 & 6.27 & 0.00 & 0.00 & 183.72 \\
\hline \multirow[t]{2}{*}{18} & Halme & 0.00 & 86.70 & 18.82 & 0.00 & 105.52 \\
\hline & Total & 4079.12 & 3017.98 & I594.94 & 760.52 & 9452.57 \\
\hline
\end{tabular}

Sumber/Source : olahan data primer (Primary data processed), (2019) 
Berdasarkan hasil penyesuaian syarat tempat tumbuh tanaman pinang dan karakteristik lahan Kecamatan Mollo Utara diperoleh kelas kesesuaian lahan SI (sangat sesuai), S2 (cukup sesuai), S3 (sesuai marjinal). Tingkat sub kelas kesesuaian $\mathrm{N}$ (tidak sesuai) sehingga diperoleh faktor pembatas (retensi hara (na), kemiringan lahan atau ketinggian tempat). Upaya perbaikan terhadap faktor pembatas dilakukan dengan harapan kelas kesesuaian lahan aktual dapat menjadi kelas kesesuaian lahan potensial. Dari faktor pembatas yang ada, pemupukan dilakukan sebagai cara untuk memanipulasi lahan, yaitu dengan menambahkan pupuk $\mathrm{K}$, misalnya $\mathrm{KCl}$, pupuk $\mathrm{N}$ misalnya Urea, dan pupuk $\mathrm{P}$ misalnya SP-36 atau pupuk majemuk yang mampu menyediakan hara N, P (Supriayadi et al., 2009). Upaya-upaya perbaikan untuk faktor pembatas kemiringan lahan atau lereng diperbaiki melalui mekanisasi dalam bentuk penanaman sejajar garis kontur bila kemiringan lahannya $<30 \%$ dan usaha perbaikan yang dilakukan harus memperhatikan aspek ekologi dan ekonomisnya, artinya apabila faktor-faktor pembatas lahan tersebut dapat diatasi kendalanya maka harus diperhitungkan apakah pengusahaan tanaman pinang tersebut masih dapat memberikan keuntungan (Hardjowigeno \& Widiatmaka, 2017).

\section{E. Strategi Pengembangan Pinang Berkelanjutan}

Proses pengambilan keputusan strategi selalu berkaitan dengan pengembangan misi, tujuan, strategi, dan kebijakan (kekuatan, kelemahan, peluang, dan ancaman) dalam kondisi saat ini (Rangkuti, 2015). Berdasarkan analisis faktor internal, faktor eksternal dan diagram analisis SWOT di atas, maka disusun matriks analisis SWOT untuk mengetahui strategi pengembangan pinang di Kecamatan
Mollo Utara, sebagaimana disajikan pada Tabel 5 berikut.

Berdasarkan Gambar 5 dihasilkan strategi yang diharapkan dapat membantu dalam pengembangan pinang di Kecamatan Mollo Utara. Salah satu strategi yang diharapkan adalah strategi strength opportunity (SO), dimana strategi ini memanfaatkan kekuatan dan peluang untuk mengembangkan pinang melalui langkah-langkah antara lain: mengembangkan vegetasi yang ada melalui penanaman pinang, dan meningkatkan peran pemerintah dalam pengembangan pinang. Dalam hal ini diperlukan peran aktif dari masyarakat mengingat pinang merupakan bagian penting dari masyarakat Kecamatan Mollo Utara yang terkait dengan tradisi sosial budaya. Strategi lain yang diharapkan adalah strategi weakness opportunity (WO) yakni dengan memanfaatkan kelemahan untuk mencapai peluang. Strategi ini lebih menekankan pada pengolahan lahan yang lebih dalam, pembuatan parit sempit, penerapan pola tanam tumpang sari dan terasering serta keaktifan pemerintah dan masyarakat dalam hal sosialisasi pentingnya tanaman pinang. Sedangkan strategi ST (Strenght Threats), strategi ini memanfaatkan kekuatan dengan menekan ancaman yang bisa dilakukan yaitu membuat peraturan tentang alih fungsi hutan, memberikan pendidikan lingkungan atau konservasi kepada masyarakat, dan upaya kerjasama antara pemerintah dan masyarakat dalam menyusun program. Alternatif strategi weakness threats (WT) dapat dilakukan melalui penerapan teknologi konservasi yang tepat dalam penggunaan lahan, mendorong pengembangan pengelolaan sumberdaya alam dan lingkungan hidup terutama jenis pinang serta meningkatkan pengetahuan masyarakat tentang budidaya pinang melalui penyuluhan dan pelatihan oleh instansi terkait. 
Tabel 5. Matriks Strategi Pengembangan Pinang

Table 5. Areca Development Strategy Matrix

\begin{tabular}{|c|c|c|}
\hline \multicolumn{2}{|r|}{ Strength } & Weaknesses \\
\hline \multicolumn{2}{|c|}{$\begin{array}{l}\text { 1. Ketersediaan lahan dan memiliki tingkat kesuburan yang } \\
\text { baik dan kandungan } \mathrm{N} \text { tinggi } \\
\text { 2. Curah hujan tinggi sehingga ketersediaan air baik untuk } \\
\text { tanaman pinang } \\
\text { 3. Suhu optimal untuk pertumbuhan tanaman pinang } \\
\text { 4. Keanekaragaman vegetasi baik pada tingkat pohon dan } \\
\text { masih dijumpai tegakan alam } \\
\text { 5. Pengembangan pinang berpotensi memberikan keuntungan } \\
\text { ekonomi yang tinggi } \\
\text { 6. Pinang merupakan tanaman budaya sehingga minat } \\
\text { masyarakat tinggi untuk mengembangkan tanaman pinang }\end{array}$} & $\begin{array}{l}\text { 1. Kedalaman tanah didominasi } 70-100 \\
\text { cm dan drainase terhambat } \\
\text { 2. Kondisi kelerengan curam } \\
\text { 3. Pada strata yang lebih tinggi } \\
\text { keanekaragaman vegetasi rendah } \\
\text { 4. Produksi pinang masih rendah } \\
\text { Pinang belum dikembangkan secara } \\
\text { optimal oleh masyarakat karena } \\
\text { pengetahuan masyarakat tentang } \\
\text { budidaya pinang masih rendah }\end{array}$ \\
\hline Opportunities & Strategi S O & Strategi W O \\
\hline $\begin{array}{l}\text { I. Meningkatnya } \\
\text { pendapatan } \\
\text { masyarakat } \\
\text { 2. Lahan sesuai untuk } \\
\text { pengembangan } \\
\text { tanaman pinang }\end{array}$ & $\begin{array}{l}\text { I. Mengembangkan vegetasi yang } \\
\text { ada dengan meningkatkan } \\
\text { penanaman pinang } \\
\text { 2. Meningkatkan peran pemerintah } \\
\text { dalam pengembangan pinang }\end{array}$ & $\begin{array}{l}\text { 1. Pengolahan lahan yang lebih dalam } \\
\text { 2. Pembuatan parit sempit } \\
\text { 3. Pola tanam tumpang sari dan } \\
\text { terasering } \\
\text { 4. Pemerintah dan masyarakat lebih } \\
\text { giat dalam mensosialisasikan } \\
\text { pentingnya menanam pinang }\end{array}$ \\
\hline Threats & Strategi S T & Strategi WT \\
\hline $\begin{array}{l}\text { I. Alih fungsi lahan } \\
\text { 2. Dampak negatif } \\
\text { masyarakat yang } \\
\text { bisa merusak } \\
\text { ekosistem pinang } \\
\text { 3. Belum ada } \\
\text { program } \\
\text { pemerintah yang } \\
\text { mendukung } \\
\text { pengembangan } \\
\text { tanaman pinang }\end{array}$ & $\begin{array}{l}\text { I. Dibuat peraturan tentang alih } \\
\text { fungsi lahan } \\
\text { 2. Memberikan atan pendidikan } \\
\text { lingkungan atau konservasi } \\
\text { kepada masyarakat } \\
\text { 3. Upaya kerjasama antara } \\
\text { pemerintah dan masyarakat } \\
\text { dalam menyusun program }\end{array}$ & $\begin{array}{l}\text { I. Penerapan teknologi konservasi } \\
\text { yang tepat dalam penggunaan lahan } \\
\text { 2. Mendorong pengembangan } \\
\text { pengelolaan sumberdaya alam dan } \\
\text { lingkungan hidup terutama jenis } \\
\text { pinang } \\
\text { 3. Meningkatkan pengetahuan } \\
\text { masyarakat tentang budidaya } \\
\text { pinang melalui penyuluhan dan } \\
\text { pelatihan oleh instansi terkait. }\end{array}$ \\
\hline
\end{tabular}

Sumber/Source : olahan data primer (Primary data processed), (2019)

\section{KESIMPULAN DAN SARAN}

\section{A. Kesimpulan}

Kecamatan Mollo Utara memiliki potensi pengembangan komoditas pinang berdasarkan evaluasi kesesuaian lahan. Strategi pengembangan tanaman pinang berdasarkan analisis SWOT adalah strategi strength opportunity (SO), dimana strategi ini memanfaatkan kekuatan dan peluang untuk mengembangkan pinang yang sudah ada, melalui penanaman dan meningkatkan peran pemerintah dalam pengembangan pinang sehingga tercapai pengelolaan pinang yang berkelanjutan. Faktor pembatas kesesuaian lahan pinang adalah retensi hara (na), kemiringan lahan atau ketinggian tempat. Upaya perbaikan terhadap faktor pembatas dilakukan dengan harapan produktifitas komoditas pinang dapat meningkat. 


\section{B. Saran}

Diharapkan ke depannya akan banyak penelitian tentang kesesuaian lahan komoditas unggulan di Kecamatan Mollo Utara sehingga bisa menjadi rekomendasi penyusunan strategi pengembangan komoditas lokal.

\section{DAFTAR PUSTAKA}

Asdak, C. (20|4). Hidrologi dan Pengelolaan Daerah Aliran Sungai (Keenam). Universitas Gadja Mada Press.

Basuki, T., \& Nulik, J. (2007). Peta Agroecological Zone (AEZ) Skala Tinjau Pulau Timor, Propinsi Nusa Tenggara Timur.

BMKG. (2019). Curah Hujan Stasiun Oelbubuk.

BPDAS. (20I2). Laporan Akhir Karakteristik DAS Benenai Noelmina.

BPKH. (2018). Peta Penutupan Lahan Nusa Tenggara Timur.

Djaenudin, D., H, M., H, S., \& Hidayat, A. (20II). Petunjuk Teknis Evaluasi Lahan Untuk Komoditas Pertanian (Edisi Kedu). Balai Besar Penelitian dan Pengembangan Sumberdaya Lahan Pertanian.

FAO. (1976). A Framework for Land Evaluation, soils Bulletin 32. Food and Agricultural Organization, 32.

Hardjowigeno, S. (2010). Ilmu Tanah (Ke 7). Akademika Pressindo.

Hardjowigeno, S., \& Widiatmaka. (2017). Evaluasi kesesuaian lahan dan perencanaan tataguna lahan (Keempat). Universitas Gadja Mada Press.

Mawii, M., Lalramnghinglova, H., \& Lalnuntluanga. (20I7). Effect of Slope Gradient on the Selected Soil Physico-
Chemical Properties in Arecanut Plantation of Kolasib District, Mizoram . International Journal of Scientific Research and Reviews, 6(4), 128-138. https://doi.org/ISSN: 2279-0543

Nurfatriani, F. (2006). Konsep Nilai Ekonomi Total dan Metode Penilaian Sumberdaya Hutan. Jurnal Penelitian Sosial Dan Ekonomi Kehutanan, 3(I), 3.

Odum, E. P. (1996). Dasar-dasar Ekologi (T. Samingan (ed.); Ketiga). Gadjah Mada University Press.

Rangkuti, F. (20I5). SWOT Analysis Peluang di Balik Kesulitan. PT Gramedia Pustaka Utama.

Salukh, L. (2017). Sirih Pinang, Simbol Penghargaan di Timor Tengah Selatan. Kompasiana. https://www.kompasiana. com/leksisalukh/5976dae4da l e4a35384 b0262/sirih-pinang-simbol-penghargaan

Sihombing, T. (2000). Pinang Budi Daya dan Prospek Bisnis (II). PT Penebar Swadaya.

Staples, G. W., \& Bevacqua, R. F. (2006). Areca catechu ( betel nut palm ). Traditionaltree, I.3 (August), 5-6.

Supriayadi, S., Santoso, A. I., \& Amzeri, A. (2009). Evaluasi Kesesuaian Lahan Untuk Tanaman Pangan Di Desa Bilaporah Bangkalan. Agrovigor, 2(2), II0-II7. https://doi.org// 9795777

Yuliantoro, D., Atmoko, Bambang Dwi, \& Siswo. (2016). Pohon Sahabat Air. Balai Penelitian dan Pengembangan Teknologi Pengelolaan Daerah Aliran Sungai. 